\title{
Effects of Nicotinic Acid Therapy on Plasma High Density Lipoprotein Subfraction Distribution and \\ Composition and on Apolipoprotein A Metabolism
}

\author{
James Shepherd, Christopher J. Packard, Josef R. Patsch, antonio M. \\ GotTo, JR., and O. DAVID TAUnTON, Department of Biochemistry, Royal \\ Infirmary, Glasgow, G4 OSF, Scotland, and Division of Atherosclerosis and \\ Lipoprotein Research, Department of Medicine, Baylor College of Medicine, and \\ The Methodist Hospital, Houston, Texas 77030
}

A B S TRACT This report describes the effects of pharmacologic doses $(3 \mathrm{~g} / \mathrm{d})$ of nicotinic acid on the plasma distribution and chemical composition of the high density lipoprotein (HDL) subfractions $\mathrm{HDL}_{2}$ and $\mathrm{HDL}_{3}$ and examines the influence of the drug on the metabolism of the major HDL apoproteins, apolipoproteins A-I (ApoA-I) and A-II (Apo-II).

The drug lowered plasma cholesterol $(15 \%, P<0.05)$ and triglyceride $(27 \%, P<0.01)$; the former effect a result of a fall in the amount of cholesterol associated with very low density lipoproteins $(31 \%, P<0.02)$ and low density lipoproteins $(36 \%, P<0.02)$. Conversely, it raised plasma HDL cholesterol $(23 \%, P<0.05)$ and increased (by $345 \%$ ) the plasma $\mathrm{HDL}_{2}: \mathrm{HDL}_{3}$ ratio. The latter derived from an absolute increment $(646 \%)$ in circulating $\mathrm{HDL}_{2}$, coupled with a fall $(47 \%)$ in $\mathrm{HDL}_{3}$. This change was not associated with major alterations in the overall cholesterol (free and esterified), triglyceride, phospholipid, or protein content of the subfractions; however, it was accompanied by substantial changes in their protein composition. In particular, the molar ratio of ApoA-I:ApoA-II in $\mathrm{HDL}_{3}$ declined from 2.7:1 to 2.1:1 during nicotinic acid treatment.

Significant perturbations of ApoA-I and ApoA-II metabolism accompanied the drug-induced HDL subfraction redistribution. Specifically, the plasma concentration of ApoA-I rose by $7 \%(P<0.05)$ because of a decrease in its fractional catabolic rate. Moreover, whereas before treatment 6 and $94 \%$ of the plasma ApoA-I circulated with $\mathrm{HDL}_{2}$ and $\mathrm{HDL}_{3}$, after commencement of nicotinic acid therapy this distribution

\footnotetext{
A portion of this work has appeared in abstract form (1).

Received for publication 17 August 1978 and in revised form 27 December 1978.
}

became 49 and $51 \%$ in $\mathrm{HDL}_{2}$ and $\mathrm{HDL}_{3}$, respectively. ApoA-II was found mainly in $\mathrm{HDL}_{3}$, both before and during nicotinic acid treatment. Administration of the drug caused a $14 \%$ reduction in its plasma concentration $(P<0.05)$, which derived principally from a fall $(22 \%, P<0.01)$ in its synthetic rate.

These data suggest that the effects of nicotinic acid on the HDL subfraction distribution may be mediated via (a) net transfer of ApoA-I from $\mathrm{HDL}_{3}$ to $\mathrm{HDL}_{2}$ and (b) a reduction in ApoA-II synthesis. Our present understanding of the association between HDL and atherosclerosis indicates that such changes may have prophylactic value in the prevention of coronary artery disease.

\section{INTRODUCTION}

Prospective $(2,3)$ and retrospective $(4,5)$ epidemiological studies have shown that susceptibility to coronary artery disease is negatively correlated with the plasma high density lipoproteins (HDL) ${ }^{1}$ (density $[D]=1.063-1.210 \mathrm{~g} / \mathrm{ml}$ ) cholesterol concentration, which suggests that these lipoproteins possess antiatherogenic properties. By extrapolation, these findings may explain the observed lower incidence of coronary atherosclerosis in premenopausal women than in agematched males (6) as plasma levels of HDL cholesterol are significantly higher in the former group (7). A number of laboratories have examined this sex-related difference with HDL subfractionation techniques. For example, in an early study of this kind, Barclay et al. (8)

\footnotetext{
${ }^{1}$ Abbreviations used in this paper: ApoA-I, apolipoprotein A-I; ApoA-II, apolipoprotein A-II; ApoC, the C apolipoproteins; D, density; FCR, fractional clearance rate; HDL, high density lipoproteins; $\mathrm{HDL}_{2}, \mathrm{HDL}$ subfraction 2 ; $\mathrm{HDL}_{3}, \mathrm{HDL}$ subfraction 3; VLDL, very low density lipoprotein.
} 
have demonstrated that the plasma HDL subfraction 2 $\left(\mathrm{HDL}_{2}\right)(\mathrm{D}=1.063-1.125 \mathrm{~g} / \mathrm{ml})$ level in premenopausal women is more than twice that found in men of the same age: an observation confirmed in recent investigations. Cheung and Albers (9) have noted a similar increase in the $\mathrm{HDL}_{2}$ cholesterol level in females, but failed to detect any intersex difference in HDL subfraction $3\left(\mathrm{HDL}_{3}\right)(\mathrm{D}=1.125-1.210 \mathrm{~g} / \mathrm{ml})$ cholesterol, which suggests that the putative protection conferred by HDL against atherosclerosis $(2-4,10)$ may reside specifically in the $\mathrm{HDL}_{2}$ subfraction.

Two pharmacologic agents, nicotinic acid and clofibrate, are known to perturb the plasma HDL subfraction distribution, thus causing a significant rise in $\mathrm{HDL}_{2}(11,12)$. Nicotinic acid is more effective in this respect, increasing the $\mathrm{HDL}_{2}: \mathrm{HDL}_{3}$ ratio by at least $300 \%$ (11). This change is associated with a fall in the fractional clearance rate of total HDL protein from the plasma compartment and an increase in the ratio of apolipoprotein A-I (ApoA-I):apolipoprotein A-II (ApoA-II), the major HDL apoproteins, in the plasma (11). Because the latter ratio is higher in $\mathrm{HDL}_{2}$ than in $\mathrm{HDL}_{3}(9,13)$ we surmised that the altered HDL subfraction distribution produced by the drug might be associated with relative changes in the metabolism of these proteins. In this study, we have examined this possibility by measuring the kinetic parameters of ApoA-I and ApoA-II and the composition of circulating $\mathrm{HDL}_{2}$ and $\mathrm{HDL}_{3}$ before and during the administration of nicotinic acid to five healthy subjects.

\section{METHODS}

This project was approved by the Human Research Committees of Glasgow Royal Infirmary, Baylor College of Medicine, and The Methodist Hospital. Five healthy young adults (three male, two female) were examined on two occasions, first while receiving no medication (including the contraceptive pill), and secondly during nicotinic acid administration ( $1 \mathrm{~g}$ thrice daily by mouth). The subjects had formed part of a previously examined group (14) whose clinical, biochemical, and hematological parameters were within the normal range. They ate a regular diet and were examined as outpatients, an arrangement which minimized perturbation of their life-styles and which has been shown (15) to provide steady-state conditions suitable for turnover studies. For $3 \mathrm{~d}$ before and throughout the investigations, they received $300 \mathrm{mg}$ of potassium iodide thrice daily to prevent thyroidal sequestration of radioiodide.

Turnover study protocol. In the first, control phase of this study, base-line measurements were made of HDL apoprotein metabolism and of the relative distribution and composition of the HDL subfractions in each subject. Thereafter, all participants received $1.0 \mathrm{~g}$ of nicotinic acid thrice daily for 3 wk before reassessment of the above parameters during drug treatment.

The analytical procedures which were used have been described in detail elsewhere $(14,16,17)$. Essentially, autologous HDL was labeled with ${ }^{131}$ I-ApoA-I and ${ }^{125}$ I-ApoA-II by an in vitro transfer procedure $(16,17)$, and the plasma clearance rate of the proteins was determined as described before (14) with the mathematical procedures of Matthews (18) and Berson and Yalow (19) for data analysis. Uptake of the labeled apoproteins into HDL isolated before or during nicotinic acid treatment was not measurably different, and agarose gel chromatography (14) showed that throughout both study periods the labeled tracer apoproteins remained associated with the plasma HDL fraction. The plasma concentrations of ApoA-I and ApoA-II in each subject were measured at daily intervals throughout the turnover study by previously published electroimmunoassay methods $(14,20)$ whose within- and between-batch coefficients of variation were 3.6 and $4.8 \%$ for ApoA-I and 4.5 and $4.6 \%$ for ApoA-II. The frequency of plasma sampling for the estimation of plasma lipids and lipoproteins is detailed elsewhere (14).

Rate zonal ultracentrifugation. At the end of each phase of the study, $\mathrm{HDL}_{2}$ and $\mathrm{HDL}_{3}$ in the plasma of each subject were isolated by rate zonal ultracentrifugation (21). The separated subfractions were dialysed exhaustively against $0.15 \mathrm{M} \mathrm{NaCl} / 0.01 \%$ disodium EDTA in $0.01 \mathrm{M}$ Tris buffer (pH 7.0) before concentration by ultrafiltration through an Amicon XM 100 cellulose membrane (Amicon Corp., Lexington, Mass.). The composition of the fractions was determined by estimation of protein (22), phospholipid (as inorganic phosphorous [23]), triglyceride (Boehringer kit 126012, Boehringer Mannheim Biochemicals, Indianapolis, Ind.), and free and esterified cholesterol (Boehringer kit 124087, Boehringer Mannheim Biochemicals). The ApoA-I and ApoA-II content of the subfractions was measured by electroimmunoassay $(14,20)$.

Finally, the relative distribution of $\mathrm{HDL}_{2}$ and $\mathrm{HDL}_{3}$ in the plasma was determined from the areas subtended by the respective peaks of each subfraction on the zonal elution profile (20).

\section{RESULTS}

Effect of nicotinic acid treatment on plasma lipids and lipoproteins. Administration of nicotinic acid in a dose of $3 \mathrm{~g} / \mathrm{d}$ lowered the plasma cholesterol and triglyceride concentrations (Table I) in this group of normal subjects by a mean of $15(P<0.05)$ and $27 \%$ $(P<0.01)$, respectively. The fall in cholesterol resulted from a significant reduction in the amount of that lipid transported in the very low density lipoprotein (VLDL) $(\mathrm{D}=0.95-1.006 \mathrm{~g} / \mathrm{ml})(31 \% \downarrow, P<0.02)$ and low density lipoprotein $(\mathrm{D}=1.006-1.063 \mathrm{~g} / \mathrm{ml})(36 \% \downarrow$, $P<0.02)$ fractions of the plasma. By contrast the drug induced a substantial rise $(23 \%, P<0.05)$ in $\mathrm{HDL}$ cholesterol (Table I), accompanied by alterations in the HDL subfraction distribution. Fig. 1 shows typical HDL rate zonal ultracentrifugation profiles of a male and female subject before and during treatment. In the control situation, the characteristic sex-related difference (21) in the $\mathrm{HDL}_{2}: \mathrm{HDL}_{3}$ ratio is evident, the male ratio being substantially lower than that of the female. Nicotinic acid produced, in the male subject, a large increase in $\mathrm{HDL}_{2}$, whereas in the female the increase in $\mathrm{HDL}_{2}$ was also accompanied by an evident reduction in the level of $\mathrm{HDL}_{3}$. Individual values for the $\mathrm{HDL}_{2}: \mathrm{HDL}_{3}$ ratio are given in Table II and show that this treatment consistently gave rise to a higher $\mathrm{HDL}_{2}$ : $\mathrm{HDL}_{3}$ ratio in the plasma, the mean increment being $345 \%$. 
TABLE I

Effects of Nicotinic Acid Therapy on Plasma Lipids and Lipoproteins

\begin{tabular}{|c|c|c|c|c|c|c|c|c|c|c|c|c|c|}
\hline \multirow{2}{*}{$\begin{array}{l}\text { Subject } \\
\text { (sex) }\end{array}$} & \multirow[b]{2}{*}{ Age } & \multicolumn{2}{|c|}{$\begin{array}{l}\text { Body weight } \\
\quad(n=15)\end{array}$} & \multicolumn{2}{|c|}{$\begin{array}{c}\text { Plasma } \\
\text { cholesterol } \\
(n=7)\end{array}$} & \multicolumn{2}{|c|}{$\begin{array}{c}\text { Plasma } \\
\text { triglyceride } \\
(n=7)\end{array}$} & \multicolumn{2}{|c|}{$\begin{array}{c}\text { VLDL } \\
\text { cholesterol } \\
(n=5)\end{array}$} & \multicolumn{2}{|c|}{$\begin{array}{c}\text { LDL } \\
\text { cholesterol } \\
(n=5)\end{array}$} & \multicolumn{2}{|c|}{$\begin{array}{c}\text { HDL } \\
\text { cholesterol } \\
(n=15)\end{array}$} \\
\hline & & $\mathrm{C}^{*}$ & $\mathbf{N}$ & C & $\mathbf{N}$ & C & $\mathbf{N}$ & C & $N$ & C & $N$ & $\mathrm{C}$ & $\mathbf{N}$ \\
\hline & $y r$ & \multicolumn{2}{|c|}{$k g$} & \multicolumn{2}{|c|}{$m g / d l$} & \multicolumn{2}{|c|}{$m g / d l$} & \multicolumn{2}{|c|}{$m g / d l$} & \multicolumn{2}{|c|}{$m g / d l$} & \multicolumn{2}{|c|}{$\mathrm{mg} / \mathrm{dl}$} \\
\hline B.S. (M) & 27 & $116.2 \pm 0.5$ & $114.9 \pm 0.7$ & $155 \pm 9$ & $155 \pm 6$ & $131 \pm 44$ & $95 \pm 23$ & $28 \pm 10$ & $17 \pm 4$ & $85 \pm 13$ & $75 \pm 12$ & $37 \pm 8$ & $52 \pm 5$ \\
\hline J.B. (M) & 23 & $80.5 \pm 0.5$ & $79.3 \pm 0.7$ & $153 \pm 8$ & $113 \pm 12$ & $80 \pm 24$ & $61 \pm 14$ & $12 \pm 3$ & $8 \pm 2$ & $92 \pm 13$ & $39 \pm 13$ & $43 \pm 7$ & $55 \pm 7$ \\
\hline K.W. (M) & 24 & $68.4 \pm 0.6$ & $67.8 \pm 0.4$ & $171 \pm 4$ & $145 \pm 7$ & $65 \pm 13$ & $48 \pm 6$ & $14 \pm 5$ & $8 \pm 5$ & $93 \pm 12$ & $65 \pm 22$ & $52 \pm 8$ & $69 \pm 11$ \\
\hline C.C. $(\mathrm{F})$ & 29 & $58.2 \pm 0.4$ & $58.3 \pm 0.2$ & $174 \pm 11$ & $145 \pm 7$ & $60 \pm 8$ & $39 \pm 9$ & $14 \pm 4$ & $10 \pm 3$ & $102 \pm 10$ & $58 \pm 12$ & $63 \pm 11$ & $81 \pm 13$ \\
\hline S.W. (F) & 24 & $57.4 \pm 0.5$ & $57.6 \pm 0.6$ & $165 \pm 6$ & $139 \pm 19$ & $60 \pm 7$ & $45 \pm 13$ & $14 \pm 2$ & $10 \pm 4$ & $85 \pm 7$ & $55 \pm 23$ & $66 \pm 10$ & $65 \pm 6$ \\
\hline \multicolumn{4}{|c|}{ Mean \pm 1 SD } & $163 \pm 9$ & $139 \pm 16$ & $79 \pm 30$ & $58 \pm 22$ & $16 \pm 6$ & $11 \pm 4$ & $91 \pm 7$ & $58 \pm 13$ & $52 \pm 12$ & $64 \pm 12$ \\
\hline$P$ & & \multicolumn{2}{|c|}{ NS $\ddagger$} & \multicolumn{2}{|c|}{$<0.05$} & \multicolumn{2}{|c|}{$<0.01$} & \multicolumn{2}{|c|}{$<0.02$} & \multicolumn{2}{|c|}{$<0.02$} & \multicolumn{2}{|c|}{$<0.05$} \\
\hline
\end{tabular}

$n$, number of experiments, LDL, low density lipoprotein.

* $\mathrm{C}$, control; $\mathrm{N}$, nicotinic acid treatment.

\& Statistics obtained by paired $t$ test.

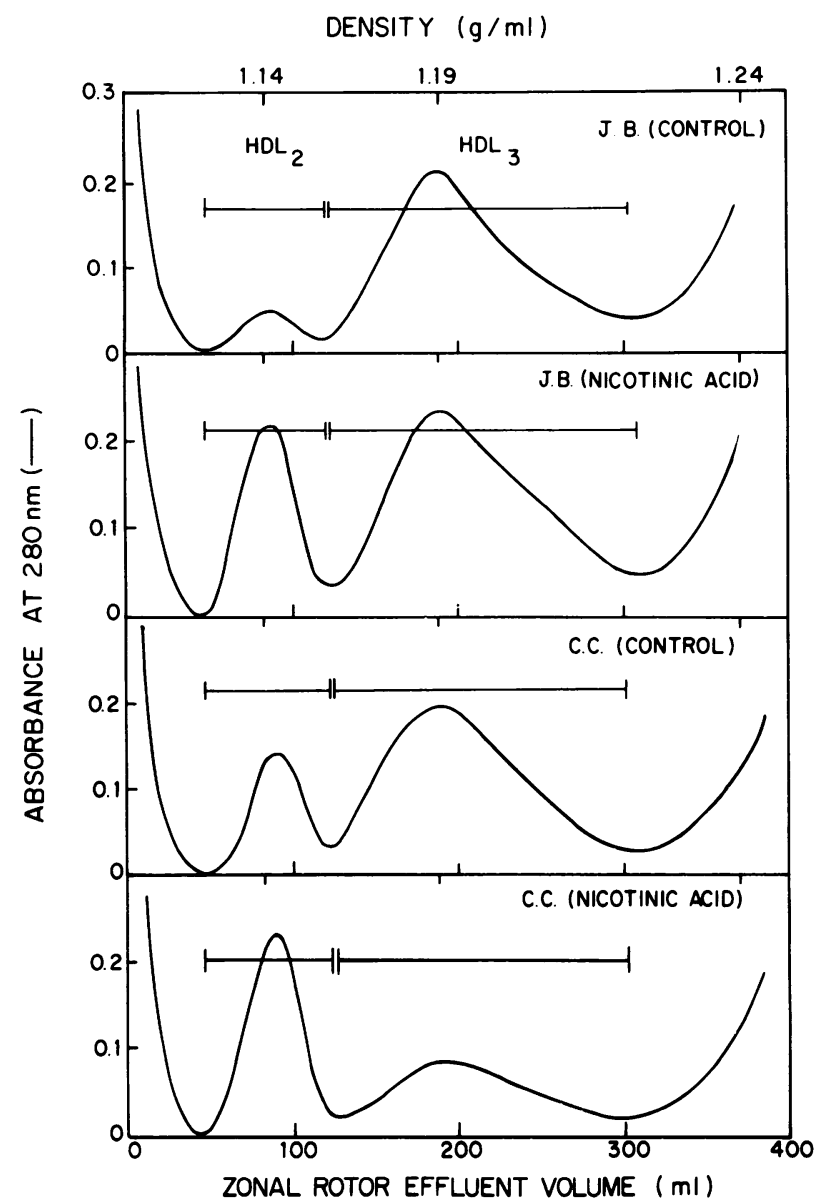

FIGURE 1 HDL rate zonal ultracentrifugation profile of J.B. (male) and C.C. (female) before and during nicotinic acid treatment. Each pattern was obtained by centrifugation of $15-\mathrm{ml}$ aliquots of fasting plasma in a $1.0-$ to $1.4-\mathrm{g} / \mathrm{ml}$ discontinuous $\mathrm{NaBr}$ gradient by the method of Patsch et al. (21).
Concomitant with the above changes, small but significant modifications were observed in the plasma levels of ApoA-I and ApoA-II (Table II). Specifically, the concentration of ApoA-I rose by a mean of $7 \%$ $(\mathrm{P}<0.05)$ whereas that of ApoA-II fell $14 \%(P<0.05)$. Consequently, the plasma ratio of these proteins was significantly changed as a result of the treatment (Table II). When compared with the control value, the ApoA-I:ApoA-II ratio increased by $26 \%(P<0.01)$ during nicotinic acid administration.

Influence of nicotinic acid on the composition of $H D L_{2}$ and $H D L_{3}$. Chemical analysis of the HDL subfractions (Tables III and IV) indicated that the marked drug-induced alteration in their plasma distribution was not accompanied by major changes in the particles' overall protein, triglyceride, phospholipid, or cholesterol (free and esterified) content. In the control situation, the major protein component of both subfractions was found to be ApoA-I (comprising 55.8 and $65.8 \%$ of the protein complement of $\mathrm{HDL}_{2}$ and $\mathrm{HDL}_{3}$, respectively; Tables III and IV). Conversely, ApoA-II was largely associated with $\mathrm{HDL}_{3}$ (accounting for $15 \%$ of its protein mass), only trace amounts $(<2 \%$ of the protein in the particle) being found in $\mathrm{HDL}_{2}$. These two proteins taken together accounted for 58 and $79 \%$ of the control $\mathrm{HDL}_{2}$ and $\mathrm{HDL}_{3}$ protein, respectively. Nicotinic acid treatment increased the percentage of ApoA-I and ApoA-II in $\mathrm{HDL}_{2}$ to a mean of 79.3 and $4.3 \%$, and in $\mathrm{HDL}_{3}$ to 75.1 and $21.4 \%$ of the total protein, respectively. The identity of the residual proteins in the subfractions has not yet been established, but evidence from other laboratories $(13,24)$ suggests that the $\mathrm{C}$ apolipoproteins (ApoC) make an important contribution, particularly as components of $\mathrm{HDL}_{2}$.

Knowledge of the plasma concentrations of ApoA-I and ApoA-II (Table II) and of their contribution to 
TABLE II

Effects of Nicotinic Acid Therapy on HDL Subfraction Distribution and Plasma ApoA-I and ApoA-II Levels

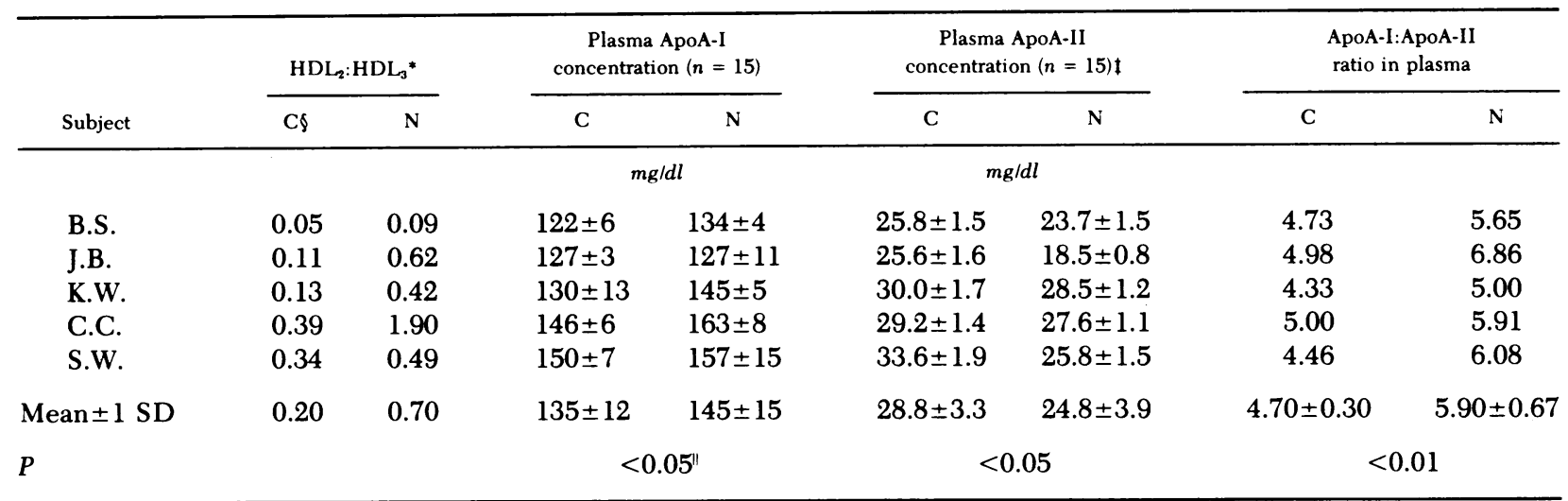

$n$, number of experiments.

* Obtained from rate zonal ultracentrifugation profiles.

$\ddagger$ Measured by electroimmunoassay $(14,19)$.

$\$ \mathrm{C}$, control; $\mathrm{N}$, nicotinic acid treatment.

"Statistics obtained by paired $t$ test.

the mass of $\mathrm{HDL}_{2}$ and $\mathrm{HDL}_{3}$ (Tables III and IV) permitted calculation of the effects of nicotinic acid treatment on the distribution of the subfractions in the plasma. The resulting data, derived from the mean values in Tables II-IV, are presented in Table $\mathrm{V}$ and show that, in the control situation, an average of $11 \%$ (9\% in the male group, $16 \%$ in the females) of the plasma $\mathrm{HDL}$ mass was $\mathrm{HDL}_{2}$, and $89 \%$ was $\mathrm{HDL}_{3}$. Separate analyses of the male and female values showed that the response to nicotinic acid therapy was essentially the same in both groups, differing only in degree. For example, although there was a mean increase of $20 \%$ in the total plasma HDL concentration during treatment, this resulted largely from a $30 \%$ rise in the level of this lipoprotein in the male group. The comparative increment in the females was only $4 \%$.
These changes in total plasma HDL concentration were associated with a substantial redistribution of the HDL subfractions in the plasma, in accord with the findings of the zonal ultracentrifugation study. The males and females showed a respective mean increase in plasma $\mathrm{HDL}_{2}$ of 784 and $395 \%$ with a fall in $\mathrm{HDL}_{3}$ of 41 and $53 \%$. Consequently, there was an absolute increase $(1,000 \%$ in the males; $587 \%$ in the females) in the plasma concentration of $\mathrm{HDL}_{2}$-associated ApoA-I, accompanied by reductions in ApoA-I (37\% in the males; $46 \%$ in the females) and ApoA-II (23\% in the males; $29 \%$ in the females) in the $\mathrm{HDL}_{3}$ fraction. Any changes in the ApoA-II content of $\mathrm{HDL}_{2}$ were too small to be reliably measured.

Thus, the nicotinic acid-induced increase in plasma $\mathrm{HDL}_{2}$ and fall in $\mathrm{HDL}_{3}$ is accompanied by $(a)$ a rise in

TABLE III

Percentage Composition of $\mathrm{HDL}_{2}$ before and during Nicotinic Acid Treatment

\begin{tabular}{|c|c|c|c|c|c|c|c|c|c|c|c|c|c|c|}
\hline \multirow[b]{3}{*}{ Subject } & \multirow{2}{*}{\multicolumn{2}{|c|}{$\begin{array}{c}\text { Free } \\
\text { cholesterol }\end{array}$}} & \multirow{2}{*}{\multicolumn{2}{|c|}{$\begin{array}{c}\text { Esterified } \\
\text { cholesterol }\end{array}$}} & \multirow{2}{*}{\multicolumn{2}{|c|}{ Triglyceride }} & \multirow{2}{*}{\multicolumn{2}{|c|}{ Phospholipid }} & \multirow{2}{*}{\multicolumn{2}{|c|}{ Total protein }} & \multicolumn{4}{|c|}{ Percentage of total protein as } \\
\hline & & & & & & & & & & & \multicolumn{2}{|c|}{ ApoA-I } & \multicolumn{2}{|c|}{ ApoA-II } \\
\hline & $\mathrm{C}^{*}$ & $\mathbf{N}$ & C & $\mathbf{N}$ & $\mathrm{C}$ & $\mathbf{N}$ & $\mathrm{C}$ & $\mathbf{N}$ & $\mathrm{C}$ & $\mathbf{N}$ & $\mathrm{C}$ & $\mathbf{N}$ & $\mathrm{C}$ & $\mathbf{N}$ \\
\hline & \multicolumn{2}{|c|}{$\%$} & \multicolumn{2}{|c|}{$\%$} & \multicolumn{2}{|c|}{$\%$} & \multicolumn{2}{|c|}{$\%$} & \multicolumn{2}{|c|}{$\%$} & \multicolumn{2}{|c|}{$\%$} & \multicolumn{2}{|c|}{$\%$} \\
\hline B.S. & 3.6 & 5.0 & 26.4 & 28.8 & 6.4 & 11.9 & 31.6 & 29.1 & 32.0 & 25.2 & 54.4 & 62.5 & 0.02 & 4.3 \\
\hline J.B. & 2.6 & 6.7 & 25.6 & 22.0 & 14.9 & 6.9 & 28.0 & 35.5 & 28.8 & 28.9 & 54.1 & 88.0 & 1.4 & 2.5 \\
\hline K.W. & 5.4 & 7.7 & 26.9 & 24.0 & 12.4 & 6.3 & 27.8 & 33.5 & 27.5 & 28.4 & 47.1 & 68.9 & 3.4 & 5.1 \\
\hline C.C. & 6.3 & 7.4 & 25.8 & 22.6 & 7.3 & 3.5 & 32.5 & 36.6 & 28.1 & 29.8 & 60.3 & 92.9 & 2.2 & 5.5 \\
\hline S.W. & 6.0 & 7.8 & 24.7 & 23.6 & 6.4 & 4.3 & 35.5 & 36.8 & 27.4 & 27.4 & 63.1 & 84.4 & 1.8 & 3.9 \\
\hline Mean \pm 1 SD & $4.8 \pm 1.6$ & $6.9 \pm 1.2$ & $25.9 \pm 0.8$ & $24.2 \pm 2.7$ & $9.5 \pm 4.0$ & $6.6 \pm 3.3$ & $31.1 \pm 3.2$ & $34.3 \pm 3.2$ & $28.8 \pm 1.9$ & $27.9 \pm 1.8$ & $55.8 \pm 6.2$ & $79.3 \pm 13.0$ & $1.8 \pm 1.2$ & $4.3 \pm 1.2$ \\
\hline \multicolumn{11}{|l|}{$P$} & \multicolumn{2}{|c|}{$<0.01 \downarrow$} & \multicolumn{2}{|c|}{$<0.02$} \\
\hline
\end{tabular}

* $\mathrm{C}$, control; $\mathrm{N}$, nicotinic acid treatment.

Statistics obtained by paired $t$ test. 
TABLE IV

Percentage Composition of $\mathrm{HDL}_{3}$ before and during Nicotinic Acid Treatment

\begin{tabular}{|c|c|c|c|c|c|c|c|c|c|c|c|c|c|c|}
\hline \multirow[b]{3}{*}{ Subject } & \multirow{2}{*}{\multicolumn{2}{|c|}{ Free cholesterol }} & \multirow{2}{*}{\multicolumn{2}{|c|}{$\begin{array}{c}\text { Esterified } \\
\text { cholesterol }\end{array}$}} & \multirow{2}{*}{\multicolumn{2}{|c|}{ Triglyceride }} & \multirow{2}{*}{\multicolumn{2}{|c|}{ Phospholipid }} & \multirow{2}{*}{\multicolumn{2}{|c|}{ Total protein }} & \multicolumn{4}{|c|}{ Percentage of total protein as } \\
\hline & & & & & & & & & & & \multicolumn{2}{|c|}{ ApoA-I } & \multicolumn{2}{|c|}{ ApoA-II } \\
\hline & $\mathrm{C}^{*}$ & $\mathbf{N}$ & C & $\mathbf{N}$ & $\mathrm{C}$ & $\mathbf{N}$ & $\mathrm{C}$ & $\mathbf{N}$ & $\mathrm{C}$ & $\mathbf{N}$ & $\mathrm{C}$ & $\mathbf{N}$ & $\mathrm{C}$ & $\mathbf{N}$ \\
\hline & \multicolumn{2}{|c|}{$\%$} & \multicolumn{2}{|c|}{$\%$} & \multicolumn{2}{|c|}{$\%$} & \multicolumn{2}{|c|}{$\%$} & \multicolumn{2}{|c|}{$\%$} & \multicolumn{2}{|c|}{$\%$} & \multicolumn{2}{|c|}{$\%$} \\
\hline B.S. & 2.1 & 2.0 & 18.8 & 20.4 & 3.6 & 4.0 & 26.0 & 27.6 & 49.5 & 46.1 & 69.4 & 79.9 & 14.7 & 17.7 \\
\hline J.B. & 2.0 & 2.5 & 20.4 & 18.0 & 3.9 & 4.5 & 22.9 & 27.7 & 50.7 & 47.3 & 69.0 & 75.1 & 15.1 & 19.8 \\
\hline K.W. & 2.3 & 3.1 & 21.2 & 19.9 & 2.6 & 3.8 & 24.1 & 23.9 & 49.9 & 49.3 & 65.7 & 71.6 & 15.3 & 23.7 \\
\hline C.C. & 2.6 & 2.9 & 20.5 & 21.6 & 3.1 & 3.9 & 24.4 & 25.7 & 49.3 & 45.9 & 55.5 & 65.9 & 13.7 & 23.0 \\
\hline S.W. & 2.0 & 2.4 & 20.5 & 20.4 & 3.6 & 3.7 & 27.4 & 27.2 & 46.5 & 46.2 & 69.1 & 82.8 & 15.2 & 22.7 \\
\hline Mean \pm 1 SD & $2.2 \pm 0.25$ & $2.6 \pm 0.4$ & $20.3 \pm 0.9$ & $20.1 \pm 1.3$ & $3.4 \pm 0.5$ & $4.0 \pm 0.3$ & $25.0 \pm 1.8$ & $26.4 \pm 1.6$ & $49.2 \pm 1.6$ & $46.9 \pm 1.4$ & $65.8 \pm 5.9$ & $75.1 \pm 6.7$ & $14.8 \pm 0.7$ & $21.4 \pm 2.5$ \\
\hline$P \neq$ & & & & & & & & & & & $<0$ & 01 & $<0$. & 001 \\
\hline
\end{tabular}

* C, control; $\mathrm{N}$, nicotinic acid treatment.

I Statistics obtained by paired $t$ test.

the plasma ApoA-I concentration, $(b)$ an increase in plasma $\mathrm{HDL}_{2}$-associated ApoA-I with a reciprocal change in $\mathrm{HDL}_{3},(c)$ a decrease in the plasma ApoA-II level, $(d)$ a fall in the amount of ApoA-II associated with $\mathrm{HDL}_{3}$ in the plasma, and $(e)$ a significant $(22 \%)$ decrease in the ApoA-I:ApoA-II ratio in $\mathrm{HDL}_{3}(P<0.01)$.
Effects of nicotinic acid therapy of apolipoprotein A metabolism. In an earlier study (17) we have shown that the turnover of ${ }^{125} \mathrm{I}$-ApoA-II intercalated into HDL in vitro is indistinguishable from that of endogenous ApoA-II labeled in situ in the HDL particle. Consequently, because endogenous ApoA-I and ApoA-II are catabolized identically in $\mathrm{HDL}(11,17)$, the kinetic

TABLE V

Effects of Nicotinic Acid Therapy on the Distribution of ApoA-I and ApoA-II between HDL Subfractions*

\begin{tabular}{|c|c|c|c|c|c|c|c|c|c|}
\hline \multirow[b]{2}{*}{ Parameter } & \multicolumn{3}{|c|}{ Control } & \multicolumn{3}{|c|}{ Nicotinic acid treatment } & \multicolumn{3}{|c|}{$\begin{array}{l}\text { Percent change on } \\
\text { nicotinic acid }\end{array}$} \\
\hline & Male & Female & Mean & Male & Female & Mean & Male & Female & Mean \\
\hline $\begin{array}{l}\text { Plasma } \mathrm{HDL}_{2} \\
\text { concentration, } \\
\text { mg/dl }\end{array}$ & 38 & 88 & 50 & 298 & 348 & 323 & 784 & 395 & 646 \\
\hline $\begin{array}{l}\text { Plasma } \mathrm{HDL}_{3} \\
\text { concentration, } \\
\text { mg/dl }\end{array}$ & 354 & 446 & 392 & 210 & 209 & 209 & 41 & 53 & 47 \\
\hline $\begin{array}{l}\text { Total plasma HDL } \\
\text { concentration, } \\
m g / d l\end{array}$ & 392 & 534 & 442 & 508 & 557 & 532 & 30 & 4 & 20 \\
\hline $\begin{array}{l}\text { Plasma concentration } \\
\text { of } \mathrm{HDL}_{2} \text {-associated } \\
\text { ApoA-I, } m g / d l\end{array}$ & 6 & 15 & 8 & 60 & 88 & 71 & $10^{3}$ & 587 & 888 \\
\hline $\begin{array}{l}\text { Plasma concentration } \\
\text { of } \mathrm{HDL}_{3} \text {-associated } \\
\text { ApoA-I, } m g / d l\end{array}$ & 121 & 133 & 127 & 76 & 72 & 74 & 37 & 46 & 42 \\
\hline $\begin{array}{l}\text { Plasma concentration } \\
\text { of } \mathrm{HDL}_{2} \text {-associated } \\
\text { ApoA-II, } m g / d l\end{array}$ & 0.2 & 0.5 & 0.3 & 3.2 & 4.7 & 3.9 & - & - & - \\
\hline $\begin{array}{l}\text { Plasma concentration } \\
\text { of } \mathrm{HDL}_{3} \text {-associated } \\
\text { ApoA-II, } m g / d l\end{array}$ & 26.6 & 31.0 & 28.5 & 20.4 & 22.0 & 21.0 & 23 & 29 & 26 \\
\hline
\end{tabular}

* Calculated from $\mathrm{HDL}_{2}$ and $\mathrm{HDL}_{3}$ compositions (Tables III and IV) and from plasma ApoA-I and ApoA-II concentrations (Table II).

\$ ApoA-II was barely detectable in $\mathrm{HDL}_{2}$ of males and females, both before and during nicotinic acid treatment. 
parameters obtained for the ${ }^{125}$ I-ApoA-II/HDL tracer used in this study reflect the metabolism of ApoA-I and ApoA-II in holo-HDL and can be used, in conjunction with the measured ApoA-I and ApoA-II plasma pool sizes, to calculate the synthetic rates of these proteins. Radioiodinated ApoA-I, however, incorporated into HDL by the same in vitro transfer procedure $(16,17)$, is cleared from the plasma more rapidly than its counterpart labeled in holo-HDL and is thought to reflect the catabolism of an exchangeable ApoA-I subpopulation in HDL (16). The steady-state conditions which pertained throughout the study, as indicated by the low standard deviation in the measurements made of the subjects' body weight, urine:plasma radioactivity ratios, and plasma levels of cholesterol, ApoA-I, and ApoA-II (Tables I, II, and VI) validated the application of Matthews' (18) mathematical procedure. The resultant data are shown in Tables VI and VII. The nicotinic acid-induced changes in plasma ApoA-I and ApoA-II levels occurred without detectable change in the intercompartmental distribution of these proteins (Tables VI and VII), which suggests that the whole body ApoA-I pool had been increased while that of ApoA-II had fallen. The rise in plasma ApoA-I did not result from an increase in its synthesis but rather from a decrease $(P<0.01)$ in its overall fractional clearance rate (FCR) (as measured by the ${ }^{125} \mathrm{I}-\mathrm{ApoA}-\mathrm{II} / \mathrm{HDL}$ tracer, Table VI). There was no similar reduction in the FCR of the rapidly metabolised ApoA-I component (reflected in the unchanged FCR of ${ }^{131}$ I-ApoA-I/HDL during nicotinic acid treatment, Table VII). The observed reduction in plasma ApoA-II was mediated by changes in both its synthesis and catabolism. specifically, its synthetic rate fell by $22 \%(P<0.01)$ while its FCR decreased $8 \%$.

\section{DISCUSSION}

Two independent methods have been published for the measurement of HDL apoprotein metabolism. The first, introduced by Blum et al. (11), uses radioiodinated holo-HDL as tracer and involves repeated sequential purification of ApoA-I and ApoA-II from plasma HDL. This technique has demonstrated that the plasma decay curves of both proteins are not significantly different, an observation which we have confirmed by the same methodology (17). The complexities of the technique prompted our search for an alternative, simpler procedure. We have found that labeled ApoA-I and ApoA-II can be incorporated independently into $\mathrm{HDL}$ in vitro to form a product which maintains its integrity upon injection into the bloodstream $(14,17)$. Whereas the intercalated ApoA-II decays at the same rate as ApoAI and ApoA-II labeled in holo-HDL, the plasma clearance rate of in vitro incorporated ApoA-I is consistently faster $(14,17)$, which suggests that the latter represents a more rapidly metabolised HDL ApoA-I subpopula- tion (16). This proposal gains support from two recently published abstracts. In the first of these, Zech et al. (25) injected radioiodinated ApoA-I and ApoA-II and found that their plasma decay curves and urine radioactivities were consistent with a model containing two plasma components, one decaying faster than the other. A similar finding was reported by Fidge et al. (26) for ApoA-I using ${ }^{125}$ I-HDL as tracer. In this study we set out to define the effects of nicotinic acid on HDL metabolism, employing ${ }^{131}$ I-ApoA-I/HDL and ${ }^{125}$ I-ApoA-II/ HDL as tracers for the rapidly metabolised ApoA-I subpopulation and holo-HDL apolipoprotein $\mathrm{A}$, respectively.

Nicotinic acid in pharmacologic doses $(3-6 \mathrm{~g} / \mathrm{d})$ reduces plasma triglyceride and, to a lesser extent, cholesterol $(27,28)$ by lowering the level of circulating $\operatorname{VLDL}(29,30)$ and low density lipoproteins (30). In contrast, HDL cholesterol is increased (31), an observation confirmed by this study (Table I). The drug also affects the plasma levels of the major HDL apoproteins, ApoA-I and ApoA-II (Table II). ApoA-I rose by $7 \%$ $(P<0.05)$ whereas ApoA-II fell $14 \%(P<0.05)$, resulting in a significant $(26 \%, P<0.01)$ increase in the plasma ApoA-I/ApoA-II ratio. A similar, although much smaller, nicotinic acid-induced increment in this ratio was reported by Blum et al. (11) in HDL of D 1.09-1.21 $\mathrm{g} / \mathrm{ml}$. Because it has been shown by ourselves (Tables III-V) and others (9) that $\mathrm{HDL}_{2}$ contains a significant fraction of the total plasma ApoA-I, extension of the density range studied by Blum et al. to encompass this HDL subfraction in its entirety would substantially augment their assessment of the plasma ApoA-I:ApoAII ratio, particularly during nicotinic acid treatment (which raises the plasma $\mathrm{HDL}_{2}$ concentration, Table V). Similarly, this methodologic adjustment by increasing the measured plasma apolipoprotein A pool, particularly during nicotinic acid administration, would diminish the reported reduction in apolipoprotein A synthesis which these workers attributed to the drug. Consequently, both studies agree on the influence of nicotinic acid on HDL apolipoprotein A metabolism. This report extends our understanding of the pharmacologic effects of this treatment by detailing the changes produced by the drug on the kinetic parameters of the two major HDL proteins, ApoA-I and ApoA-II, and on the composition of the HDL subfractions. The fractional rate of removal of these proteins from the plasma measured by the ${ }^{125} \mathrm{I}-\mathrm{ApoA}-\mathrm{II} / \mathrm{HDL}$ tracer (mean FCR $=0.234$ pools $/ \mathrm{d}$, Table VI) decreased by $8 \%$ (to 0.216 pools/d) during nicotinic acid treatment, in excellent agreement with the equivalent values $^{2}$ calculated by Matthews' procedure (18) from

\footnotetext{
${ }^{2}$ In their study (11), nicotinic acid administration lowered the mean ApoA-II FCR to 0.209 pools/d from a control value of $0.233 \mathrm{pools} / \mathrm{d}$.
} 


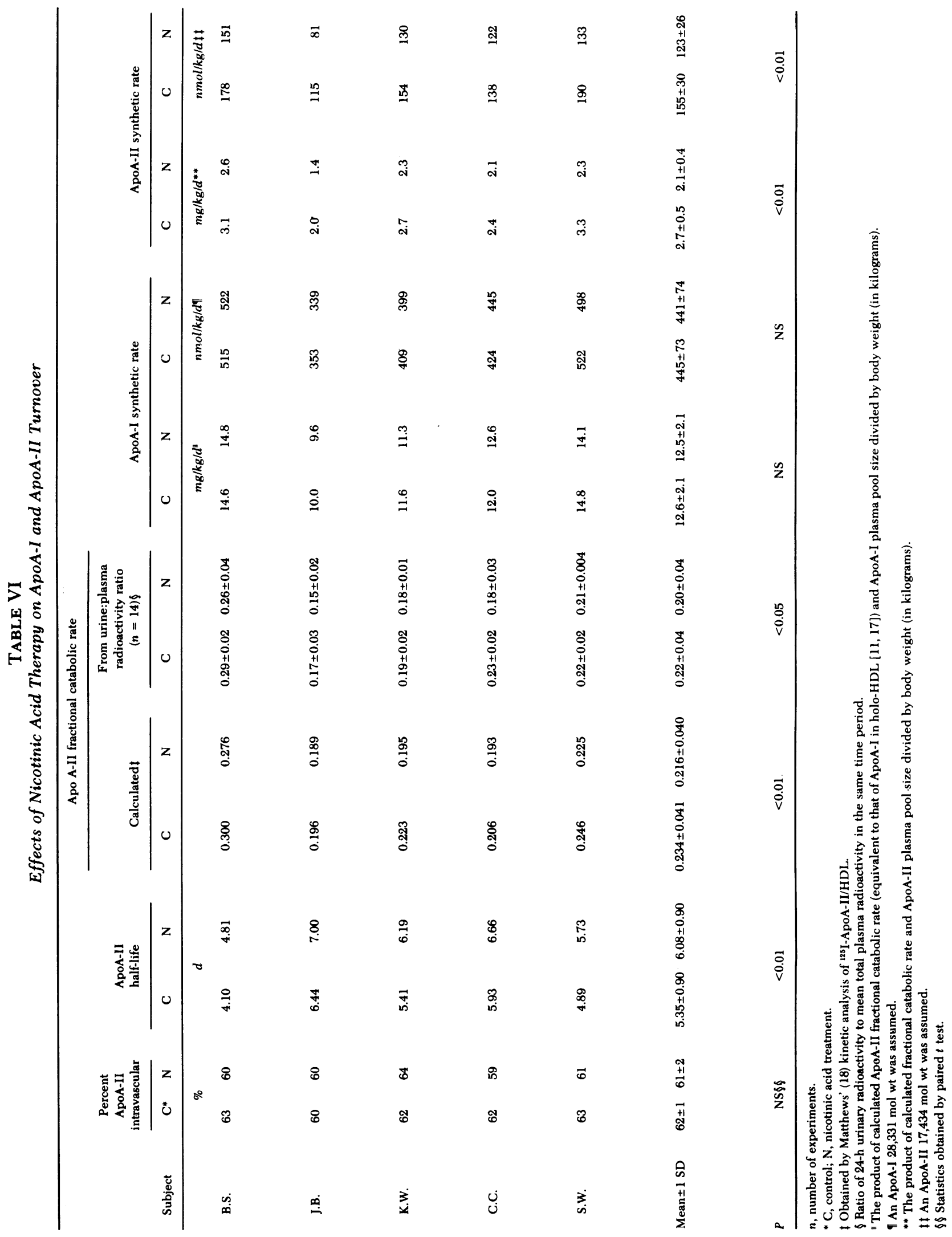


TABLE VII

Effects of Nicotinic Acid Therapy on ${ }^{131}$ I-ApoA-I/HDL Metabolism

\begin{tabular}{|c|c|c|c|c|c|c|c|c|}
\hline \multirow[b]{3}{*}{ Subject } & \multirow{2}{*}{\multicolumn{2}{|c|}{$\begin{array}{l}\text { Percent ApoA-I } \\
\text { intravascular }\end{array}$}} & \multirow{2}{*}{\multicolumn{2}{|c|}{ ApoA-I half-life }} & \multicolumn{4}{|c|}{ ApoA-I fractional catabolic rate } \\
\hline & & & & & \multicolumn{2}{|c|}{ Calculated } & \multicolumn{2}{|c|}{$\begin{array}{l}\text { From urine:plasma } \\
\text { radioactive ratio } \\
\quad(n=14) \S\end{array}$} \\
\hline & $\mathrm{C}^{*}$ & $\mathrm{~N}$ & C & $N$ & C & $\mathrm{N}$ & C & $\mathrm{N}$ \\
\hline & \multicolumn{2}{|c|}{$\%$} & \multicolumn{2}{|c|}{$d$} & & & & \\
\hline B.S. & 65 & 65 & 3.08 & 3.70 & 0.352 & 0.350 & $0.33 \pm 0.04$ & $0.38 \pm 0.03$ \\
\hline J.B. & 65 & 67 & 4.82 & 4.84 & 0.242 & 0.264 & $0.19 \pm 0.03$ & $0.25 \pm 0.03$ \\
\hline K.W. & 65 & 66 & 4.13 & 4.78 & 0.288 & 0.257 & $0.23 \pm 0.02$ & $0.26 \pm 0.02$ \\
\hline C.C. & 66 & 64 & 4.92 & 5.17 & 0.239 & 0.244 & $0.25 \pm 0.03$ & $0.24 \pm 0.05$ \\
\hline S.W. & 65 & 60 & 3.96 & 4.50 & 0.300 & 0.315 & $0.25 \pm 0.02$ & $0.29 \pm 0.05$ \\
\hline Mean \pm 1 SD & $65 \pm 0.4$ & $64 \pm 3$ & $4.18 \pm 0.74$ & $4.60 \pm 0.55$ & $0.284 \pm 0.046$ & $0.286 \pm 0.045$ & $0.25 \pm 0.05$ & $0.28 \pm 0.06$ \\
\hline$P$ & \multicolumn{2}{|c|}{$\mathbf{N S}^{\sharp}$} & \multicolumn{2}{|c|}{ NS } & \multicolumn{2}{|c|}{ NS } & \multicolumn{2}{|c|}{ NS } \\
\hline
\end{tabular}

$n$, number of experiments.

* C, control; N, nicotinic acid treatment.

† Obtained by Matthews's (18) kinetic analysis of plasma decay curve.

$\S$ Ratio of 24-h urinary radioactivity to mean total plasma radioactivity in the same time period.

"Statistics obtained by paired $t$ test.

the ApoA-II specific activity decay data of Blum et al. (11). This observation, coupled with the $7 \%$ rise in the plasma ApoA-I pool size, indicated that total ApoA-I synthesis had been unaffected by the drug (Table VI). Conversely, the $14 \%$ fall in the plasma ApoA-II pool size despite an $8 \%$ decrease in its fractional rate of catabolism was good evidence that nicotinic acid significantly reduces the synthetic rate of that protein (by $22 \%, P$ $<0.01$, Table VI). Therefore, nicotinic acid diminishes the overall rate of HDL apolipoprotein A synthesis, in accord with the conclusions of Blum et al. (11). Its influence on ApoA-I metabolism is complicated by the apparent existence of two subpopulations of this protein in the plasma $(16,25,26)$. While we are not able to determine precisely its effects on each of these, it is clear that they respond differently. The FCR of the more rapidly metabolized pool (as measured by ${ }^{131} \mathrm{I}$ ApoA-I) did not change (Table VII), whereas that of total ApoA-I (Table VI) fell significantly.

The above drug-mediated changes in apoprotein metabolism accompanied major increases in the plasma $\mathrm{HDL}_{2}: \mathrm{HDL}_{3}$ ratio without gross perturbation of the lipid composition (Tables III and IV) or flotational properties (Fig. 1) of the subfractions. Their altered distribution readily accounts for the previously observed (11) increment in the cholesterol:protein ratio of HDL during nicotinic acid treatment, because this ratio is substantially higher in $\mathrm{HDL}_{2}$ than in $\mathrm{HDL}_{3}$ (Tables III and IV).

The metabolic factors which trigger the increase in plasma $\mathrm{HDL}_{2}: \mathrm{HDL}_{3}$ during nicotinic acid therapy are difficult to evaluate because the lipoprotein appears to be affected by several direct and indirect regulatory mechanisms, some or all of which may respond to the drug. HDL is thought to be secreted by the human liver (32) in the form of nascent particles which are then extensively modified by their participation in exchange and net transfer of protein components with chylomicra $(24,33)$ and VLDL $(34,35)$. ApoA-I and ApoA-II, secreted in association with chylomicra by the gut, are quantitatively transferred to HDL during chylomicron catabolism (33). Moreover, HDL (in particular, $\mathrm{HDL}_{2}$ ) serves as a plasma reservoir for ApoC. Newly synthesised chylomicra and VLDL, on their appearance in the plasma, acquire a substantial component of their ApoC complement from this reservoir and return it during their catabolism $(24,32)$. This shuttle function of $\mathrm{HDL}_{2}$ in relation to ApoC metabolism has led to the suggestion (36) that transfer of surplus surface components from triglyceride-rich lipoproteins during lipolysis may be cardinal to regulation of the HDL subfraction distribution in the plasma. In this regard, it is arguable that the reduction in VLDL synthesis induced by the drug (29) might limit ApoC transfer from the $\mathrm{HDL}_{2}$ reservoir and account for the observed $247 \%$ expansion of the nonapolipoprotein A protein pool in the $\mathrm{HDL}_{2}$ density range (Tables III and IV) and the $646 \%$ increase in circulating $\mathrm{HDL}_{2}$ (Table V).

The changes effected by nicotinic acid on the metabolism and disposition of ApoA-I and ApoA-II in HDL favor the proposal that the shift in mean HDL 
particle size may be mediated by these proteins (11). During treatment, the rate of synthesis of ApoA-II was reduced selectively (Table VII), producing a fall in the level of that protein circulating with $\mathrm{HDL}_{3}$. The ApoAI content of the particle fell even more, evidenced by the $32 \%$ decrease in the $\mathrm{HDL}_{3}$ ApoA-I:ApoA-II molar ratio (which fell from a control value of 2.7:1 to 2.1:1 during treatment, Table IV). Yet, the synthetic rate of ApoA-I was not altered by the drug. Consequently, there had been a net loss of ApoA-I from $\mathrm{HDL}_{3}$ with an equivalent gain in $\mathrm{HDL}_{2}$ (Table $\mathrm{V}$ ). These data are consistent with the suggestion that the particle size distribution over the HDL density range may be regulated by a combination of altered synchronization of ApoA-I and ApoA-II synthesis and net transfer of ApoA-I between $\mathrm{HDL}_{2}$ and $\mathrm{HDL}_{3}$. The higher ApoA-I:ApoA-II ratio in $\mathrm{HDL}_{2}$ vs. $\mathrm{HDL}_{3}$ (Tables III and IV) and the observation that the major HDL proteins (ApoA-I, ApoA-II, and ApoC) exchange rapidly between the HDL subfractions both in vivo and in vitro (36) support this proposal.

Regulation of the plasma HDL subfraction distribution may be effected by changes in the metabolism of the HDL proteins. Such a concept links the metabolism of HDL with that of the other lipoproteins, in particular chylomicra and VLDL. However, it must be stated that the modulation attributed to the apoproteins may only play a minor regulatory role or even be subordinate to other as yet unrecognized processes. Consequently, the above hypotheses are presented as a framework for further study.

\section{ACKNOWLEDGMENTS}

We acknowledge the excellent secretarial help of Miss Annette Paterson.

This work was supported by Lipid Research Clinic Contract NH 71-2156, General Clinical Research Center grant RR 00350 from the National Institutes of Health, and by a grant from the Scottish Home and Health Department (K/MRS/ $50 / \mathrm{C} 113)$.

\section{REFERENCES}

1. Shepherd, J., C. J. Packard, J. R. Patsch, O. D. Taunton, and A. M. Gotto, Jr. 1978. The effects of nicotinic acid on plasma high density lipoprotein subfraction distribution and apoprotein metabolism. Clin. Res. 26: 271A. (Abstr.)

2. Miller, N. E., O. J. Førde, D. S. Thelle, and O. D. Mjøs. 1977. The Troms $\varnothing$ Heart Study. High density lipoprotein and coronary heart disease: a prospective case-control study. Lancet. I: 965-968.

3. Gordon, T., W. P. Castelli, M. C. Hjortland, W. B. Kannel, and T. R. Dawber. 1977. High density lipoprotein as a protective factor against coronary heart disease. The Framingham Study. Am. J. Med. 62: 707-714.

4. Rhoads, G. G., C. L. Gulbrandsen, and A. Kagan. 1976. Serum lipoproteins and coronary heart disease in a population study of Hawaii Japanese men.N. Engl.J. Med. 294: 293-298.
5. Castelli, W. P., J. T. Doyle, T. Gordon, C. G. Haines, J. C. Hjortland, S. B. Hulley, A. Kagan, and W. J. Zukel. 1977. HDL cholesterol and other lipids in coronary heart disease. The Co-operative Lipoprotein Phenotyping Study. Circulation. 55: 767-772.

6. Kannel, W. B., A. Kagan, T. R. Dawber, and N. Revotskie. 1962. Epidemiology of coronary heart disease. Geriatrics. 17: $675-686$.

7. Fredrickson, D. S. 1974. The inheritance of high density lipoprotein deficiency (Tangier disease). J. Clin. Invest. 43: 228-236.

8. Barclay, M., R. K. Barclay, and V. P. Skipski. 1963. Highdensity lipoprotein concentrations in men and women. Nature (Lond.). 200: 362-363.

9. Cheung, M. C., and J. J. Albers. 1977. The measurement of apolipoprotein A-I and A-II levels in men and women by immunoassay. J. Clin. Invest. 60: 43-50.

10. Miller, G. J., and N. E. Miller. 1975. Plasma high density lipoprotein concentration and the development of ischaemic heart disease. Lancet. I: 16-19.

11. Blum, C. B., R. I. Levy, S. Eisenberg, M. Hall, R. H. Goebel, and M. Berman. 1977. High density lipoprotein metabolism in man. J. Clin. Invest. 60: 795-807.

12. Patsch, J. R., D. Yeshurun, R. L. Jackson, and A. M. Gotto. 1977. Effects of clofibrate, nicotinic acid, and diets on the plasma lipoproteins of a subject with type III hyperlipoproteinemia. Am. J. Med. 63: 1001-1009.

13. Kostner, G. M., J. R. Patsch, S. Sailer, H. Braunsteiner, and A. Holasek. 1974. Polypeptide distribution of the main lipoprotein density classes separated from human plasma by rate zonal ultracentrifugation. Eur. J. Biochem. 45: $611-621$.

14. Shepherd, J., C. J. Packard, J. R. Patsch, A. M. Gotto, Jr., and O. D. Taunton. 1978. Metabolism of apolipoproteins A-I and A-II and its influence on the high density lipoprotein subfraction distribution in males and females. Eur. J. Clin. Invest. 8: 115-120.

15. Packard, C. J., J. L. H. C. Third, J. Shepherd, A. R. Lorimer, H. G. Morgan, and T. D. V. Lawrie. 1976. Low density lipoprotein metabolism in a family of familial hypercholesterolemic patients. Metab. Clin. Exp. 25: 995-1006.

16. Shepherd, J., A. M. Gotto, Jr., O. D. Taunton, M. J. Caslake, and E. Farish. 1977. The in vitro interaction of human apolipoprotein A-I and high density lipoproteins. Biochim. Biophys. Acta. 489: 486-501.

17. Shepherd, J., C. J. Packard, A. M. Gotto, Jr., and O. D. Taunton. 1978. A comparison of two methods to investigate the metabolism of human apolipoproteins A-I and A-II. J. Lipid Res. 19: 656-661.

18. Matthews, C. M. E. 1957. The theory of tracer experiments with ${ }^{131}$ I-labeled plasma proteins. Phys. Med. Biol. 2: 36-53.

19. Berson, S. A., and R. S. Yalow. 1957. Distribution and metabolism of ${ }^{131}$ I-labeled proteins in man. Fed. Proc. 16(Suppl. 1): 135. (Abstr.)

20. Shepherd, J., C. J. Packard, J. R. Patsch, A. M. Gotto, Jr., and O. D. Taunton. 1978. Effects of dietary polyunsaturated and saturated fat on the properties of high density lipoproteins and the metabolism of apolipoprotein A-I. J. Clin. Invest. 61: 1582-1592.

21. Patsch, J. R., S. Sailer, G. Kostner, F. Sandhofer, A. Holasek, and H. Braunsteiner. 1974. Separation of the main lipoprotein classes from human plasma by rate zonal ultracentrifugation. J. Lipid Res. 15: 356-366.

22. Lowry, O. H., N. J. Rosebrough, A. L. Farr, and R. J. Randall. 1951. Protein measurement with the Folin phenol reagent. J. Biol. Chem. 193: 265-275. 
23. Bartlett, G. R. 1959. Phosphorus assay in column chromatography. J. Biol. Chem. 234: 466-468.

24. Havel, R. J., J. P. Kane, and M. L. Kashyap. 1973. Interchange of apoproteins between chylomicrons and high density lipoproteins during alimentary lipemia in man.J. Clin. Invest. 52: 32-38.

25. Zech, L. A., E. J. Schaefer, and H. B. Brewer. 1978. Metabolism of plasma apolipoproteins A-I and A-II in man. Circulation. 57: II-40. (Abstr.)

26. Fidge, N., P. Nestel, M. Reardon, and T. Ishikawa. 1978. High density lipoprotein A-I and A-II kinetics. Circulation. 57: II-40. (Abstr.)

27. Altschul, R., A. Hoffer, and S. D. Stephen. 1955. Influence of nicotinic acid on serum cholesterol in man. Arch. Biochem. Biophys. 54: 558-563.

28. Coronary Drug Project Research Group. 1975. Clofibrate and niacin in coronary heart disease. JAMA J. Am. Med. Assoc. 231: 360-381.

29. Carlson, L. A., L. Oro, and J. Ostman. 1968. Effect of nicotinic acid on plasma lipids in patients with hyperlipoproteinaemia during the first week of treatment. J. Atheroscler. Res. 8: 667-677.

30. Carlson, L. A., A. G. Olsson, L. Oro, S. Rossner, and G. Walldius. 1974. Effects of hypolipidaemia regimes on serum lipoproteins. In Atherosclerosis III. G. Schettler and A. Weizel, editors. Springer-Verlag, Berlin. 768. (Abstr.)

31. Carlson, L. A., A. G. Olsson, and D. Ballantyne. 1977. On the rise in low density and high density lipoproteins in response to the treatment of hypertriglyceridaemias. Atherosclerosis. 26: 603-608.

32. Havel, R. J. 1978. Origin of HDL. In High Density Lipoproteins and Atherosclerosis. A. M. Gotto, Jr., N. E. Miller, and M. F. Oliver, editors. Elsevier/North Holland Biomedical Press, Amsterdam, The Netherlands. 21-35.

33. Schaefer, E. J., L. L. Jenkins, and H. B. Brewer. 1978. Human chylomicron apolipoprotein metabolism. Biochem. Biophys. Res. Commun. 80: 405-412.

34. Bilheimer, D. W., S. Eisenberg, and R. I. Levy. 1972. The metabolism of very low density lipoprotein proteins. I. Preliminary in vitro and in vivo observations. Biochim. Biophys. Acta. 260: 212-221.

35. Eisenberg, S., D. W. Bilheimer, and R. I. Levy. 1972. The metabolism of very low density lipoproteins. II. Studies on the transfer of apoproteins between plasma lipoproteins. Biochim. Biophys. Acta. 280: 94-104.

36. Shepherd, J., J. R. Patsch, C. J. Packard, A. M. Gotto, and O. D. Taunton. 1978. Dynamic properties of human high density lipoproteins apoproteins. J. Lipid Res. 19: 383-389. 